\title{
Change in The Electrical Properties Due to Modification Of The Epoxy Network Structure Using Reactive Diluents
}

\author{
Istebreq A. Saeedi, Alun S. Vaughan and Thomas Andritsch \\ The Tony Davies High Voltage Laboratory \\ University of Southampton \\ Southampton, UK, SO17 1BJ \\ iahs1e13@soton.ac.uk
}

\begin{abstract}
There is a wide range of commercial applications that utilize epoxy resin as a main insulation material. Recent studies revealed that changing the molecular structure in epoxy/anhydride systems, by the introduction of a reactive diluent, can significantly improve the electrical properties. This research is of interest for high voltage applications, because the introduction of these reactive modifiers may provide a means of tailoring the dielectric properties of epoxy resins, such as permittivity and conductivity. The results reported in this work reveal that the addition of a reactive diluents greatly affects the glass transition temperature, $T_{g}$, the permittivity, the DC conductivity and the breakdown strength. This can be explained through the reactive diluent leading to a significant modification of the epoxy network, whereby changed free volume caused by the presence of small branches alters the properties of the system. Therefore, the concept described, in principle, may be used to varying material properties in a controlled manner to tailor the properties of epoxy resins.
\end{abstract}

\section{INTRODUCTION}

In recent decades the demand for electrical power has increased significantly, which is expected to continue into the near future [1]. The increased consumption of energy is in fact a consequence of both the increasing world population and the growing economies in developing countries such as China and India. These combined with other factors result in a continuing need for new technologies to meet energy demand. Consequently, the electrical power industries face vast programs of investment and expansion, where energy generation technologies such as wind turbines and solar power plants have been implemented on large scales. This requires electrical power equipment to become larger in size and withstand higher power ratings. For reliable and secure power grids, equipment for power transmission and distribution such as switchgears, joints and cables are required to operate in an efficient manner. As the efficiency of such equipment is greatly affected by the insulation, optimized materials such as epoxy thermosetting insulating material [2]. Therefore, several attempts have been made to develop epoxy insulating material incorporating suitable additives, which would reduce the cost and improve the properties of the final epoxy system. To do this, a large and growing corpus of studies have investigated the effect of including differently sized fillers with varied chemical structures within epoxy resins. Appropriate fillers are reported to alter the dielectric permittivity [3], alter the glass transition temperature $T_{g}$ [4], and improve the breakdown strength [5]. However, such changes are not consistently seen and the effect of nano sized fillers are quite sensitive and governed by factors such as the modification of filler surface, filler size, filler concentration, the inherent chemical composition and synthesis method [3-6].

An alternative way of improving the properties of epoxy resin systems is by modifying the epoxy resin matrix at the molecular level, which can done through the introduction of active species such as reactive diluents. This has been investigated by Liu et al. [7], where it was found that the addition of epoxy based reactive diluent resulted in increased breakdown strength of the modified samples, although the added reactive diluent exhibitted no electroactive character.

In the work reported here, we investigate the broad effect of an aliphatic epoxy-based reactive diluent on electrical and thermal properties. Varied percentages of glycidyl hexadecyl ether reactive diluent were added to alter the resin matrix and their effect on the AC breakdown strength, glass transition temperature and dielectric response are described.

\section{EXPERIMENTAL}

\section{A. Materials}

The epoxy resin used in this study was a diglycidyl ether of bisphenol-A (DGEBA), namely, the commercial resin DER332 supplied by Sigma Aldrich, which has an epoxide equivalent molar mass of 172-176 $\mathrm{g} \mathrm{mol}^{-1}$. 2,3-epoxypropyl hexadecylether or glycidyl hexadecyl ether (GHE) was used as an epoxy-based reactive diluent, to modify the network structure of the base epoxy resin. The reactive diluent has a molar mass of $298.50 \mathrm{~g} \mathrm{~mol}^{-1}$ and was obtained from Sigma Aldrich. The amine hardener used to cure the mixture of resin and diluent was Jeffamine D-230 from Huntsman, which has hydrogen equivalent molar mass of $60 \mathrm{~g} \mathrm{~mol}^{-1}$. Throughout this study, the optimum theoretical stoichiometry was maintained to ensure complete reaction between the amine groups of the hardener and all epoxy groups of both the resin and the diluent. 


\section{B. Sample fabrication}

Epoxy resin samples were prepared by first weighting out the required mass of resin, diluent and amine hardener. The resin and the diluent were heated at $50{ }^{\circ} \mathrm{C}$ for at least $1 \mathrm{~h}$ to reduce their viscosity. The resin, hardener and diluent were then mixed for $5 \mathrm{~min}$ using a magnetic stirrer, before the mixture was degassed and cast in steel molds. A standard curing and post curing schedule was used for all samples, in which the samples were first cured at $80{ }^{\circ} \mathrm{C}$ for $2 \mathrm{~h}$, cooled down to room temperature and finally post-cured at $125{ }^{\circ} \mathrm{C}$ for $3 \mathrm{~h}$. The produced samples, nominally $200 \mu \mathrm{m}$ in thickness, were stored in vacuum until use. The modified epoxy resin samples contained $1-30$ mol.\% of epoxide groups from the GHE diluent. Therefore, a \%GHE naming notation is used to refer to the samples, where the \% correspond to the molar percentage of epoxide groups from the GHE reactive diluent. For example, 10GHE refer to a system containing $10 \mathrm{~mol} . \%$ of epoxide groups from the diluent while 0GHE corresponds to an unmodified formulation.

\section{Material Characterization}

Differential scanning calorimetry (DSC) experiments were conducted on samples about $10 \mathrm{mg}$ in mass. The heat capacity and $T_{g}$ of samples were studied using a Perkin Elmer DSC7 system under nitrogen gas and which was routinely calibrated using high purity indium. Two thermal cycles were applied, to each sample: each heating scan was conducted over the temperature range $20{ }^{\circ} \mathrm{C}$ to $170{ }^{\circ} \mathrm{C}$ using a heating rate of $10^{\circ} \mathrm{C} \mathrm{min}^{-1}$. Between the two scans, samples were cooled down to $20^{\circ} \mathrm{C}$ using the same rate $\left(10{ }^{\circ} \mathrm{C} \mathrm{min}^{-1}\right)$. All the data reported here were obtained from the second scan.

To study the dielectric properties and the conductivity of the samples, specimens were gold sputtered with circular gold electrodes, of diameter $30 \mathrm{~mm}$, to ensure good contact between the sample and the electrodes. A Schlumberger SI 1260 impedance / phase gain analyzer connected to Solartron 1296 dielectric interface was used to examine the dielectric response of the samples. Dielectric spectra were measured as a function of frequency from $0.1 \mathrm{~Hz}$ to $0.1 \mathrm{MHz}$ at room temperature and the amplitude of the applied AC electric voltage was set to $1 \mathrm{~V}$.

AC breakdown testing was conducted using a Phenix Type 600C system, using a $50 \mathrm{~Hz}$ AC waveform, which was increased at a rate of $50 \mathrm{~V} / \mathrm{s}$. The test cell comprised spherical steel ball bearing electrodes, which were $6.3 \mathrm{~mm}$ in diameter. Throughout the breakdown test, the sample was immersed in silicon oil and the ball bearing electrodes were changed after every 15 tests. The collected breakdown data were analyzed using Weibull 7++ software assuming a two parameter Weibull distribution.

The effect of epoxy formulation on electrical conductivity was studied using a DC electric field of $40 \mathrm{kV} / \mathrm{mm}$. For this purpose, a Keithley 6487 picoammeter was used, which was connected to $20 \mathrm{~mm}$ circular electrodes. The coated samples were placed between the two electrodes and DC conductivity data were collected at room temperature for $3 \mathrm{~h}$.

\section{RESULTS}

A. Thermal Analysis

DSC traces showing the glass transition in neat and modified epoxy resin samples are shown in Fig.1, while derived quantities are listed in Table I. The $T_{g}$ of the pure epoxy resin system was observed at about $83{ }^{\circ} \mathrm{C}$, while comparison of DSC data obtained from 0GHE, 1GHE, 4GHE and 10GHE indicates that, as the fraction of epoxide groups from the reactive diluent increases, both $T_{g}$ and heat capacity shift to lower values. In addition, the DSC trace obtained from 30GHE appears as a straight horizontal line in Fig.2, which suggests that the glass transition of this system falls below the temperature range that is accessible with the DSC used here.

\section{B. Dielectric Spectroscopy}

The dielectric response of neat and modified epoxy resin samples is shown in Fig.2. Apart from sample 30GHE, the real part of the complex permittivity of all others samples at low frequencies indicates a progressive decrease in the real part of the relative permittivity as the fraction of reactive diluent increases. We attribute the increased real permittivity of the 30GHE in this frequency range to the fact that these dielectric response measurements were conducted at room temperature which, from the above DSC data, is comparable to the glass transition temperature of this system. The variation in the imaginary part of the complex permittivity will be discussed later in this paper.

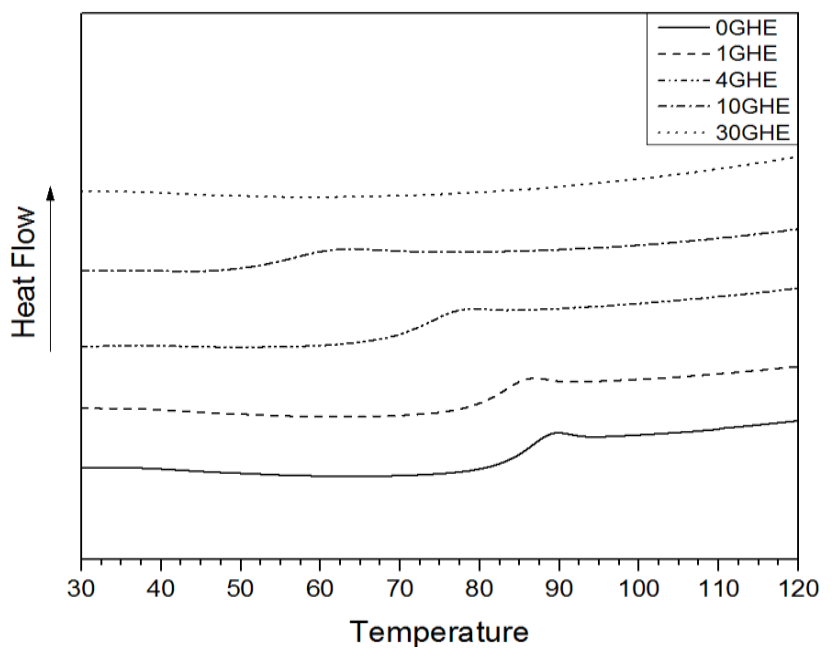

Fig. 1. Differential scanning calorimetry measurments as a function of temperature for neat and modified epoxy systems.

TABLE I. DSC DATA OF TESTED EPOXY SAMPLES

\begin{tabular}{|c|c|c|c|}
\hline Sample ID & $\boldsymbol{T g}\left({ }^{\circ} \boldsymbol{C}\right)$ & $\Delta \boldsymbol{C}\left(\boldsymbol{J} / g^{\circ} \boldsymbol{C}\right)$ & Onset $\left({ }^{\circ} \boldsymbol{C}\right)$ \\
\hline 0 GHE & 83.34 & 0.530 & 81.7 \\
\hline 1 GHE & 81.64 & 0.312 & 79.13 \\
\hline 4 GHE & 71.43 & 0.274 & 68.43 \\
\hline $10 \mathrm{GHE}$ & 53.89 & 0.211 & 50.63 \\
\hline
\end{tabular}



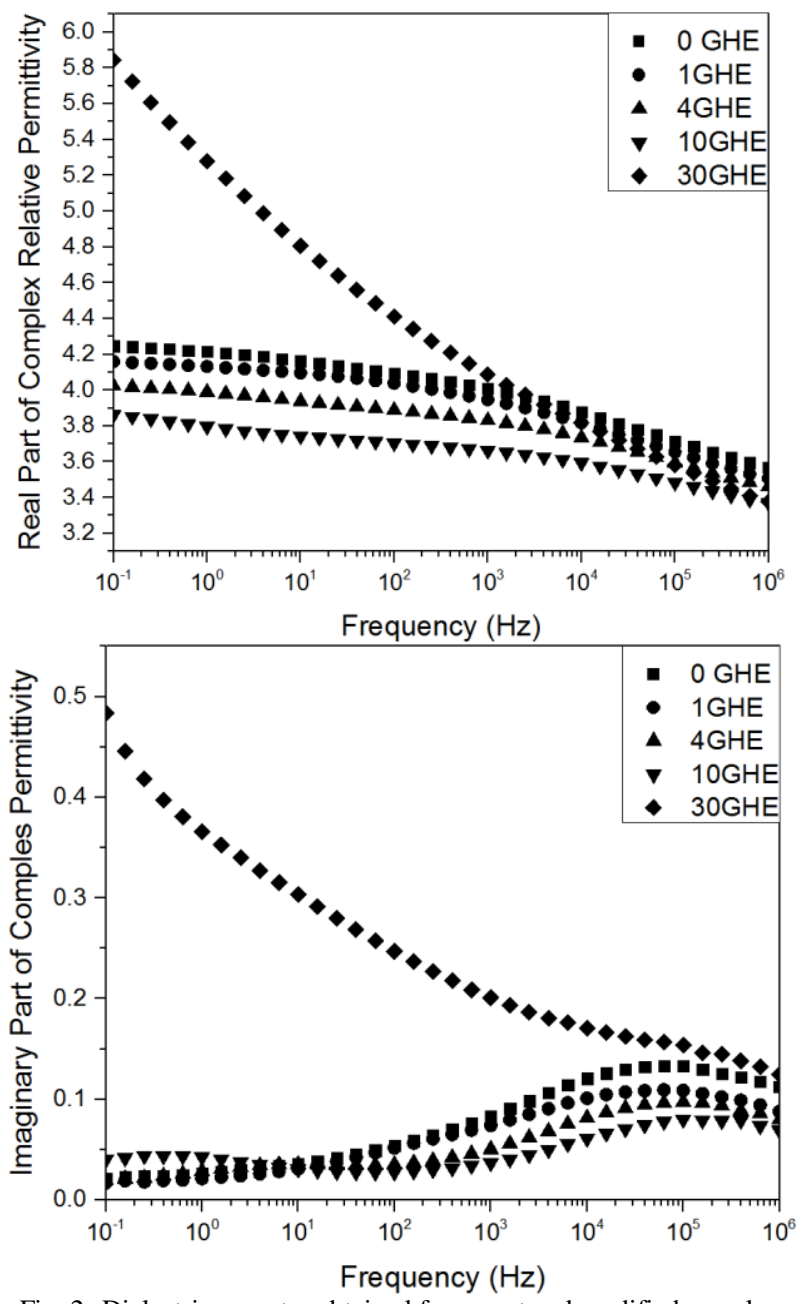

Fig. 2. Dielectrica spectra obtained from neat and modified samples.

\section{AC Breakdown test}

Fig. 3 show the effect of the reactive diluents on the breakdown strength of neat and modified epoxy resin samples. Systems with $30 \%$ of epoxide groups from GHE have a significantly lower breakdown strength, relative to the neat epoxy system. However, although the $90 \%$ confidence bounds of the $\alpha$ values of the $0 \mathrm{GHE}$ and $4 \mathrm{GHE}$ systems overlap at very low probabilities of failure (less than $3 \%$ ), systems with $4 \%$ of the epoxide groups from the reactive diluents generally perform better than system containing 0GHE. The breakdown strength data presented in Table II therefore indicated that the addition of up to $10 \%$ parts of epoxide groups from GHE may have beneficial consequences for the breakdown strength.

TABLE II. BREAKDOWN TEST DATA

\begin{tabular}{|c|c|c|}
\hline Sample ID & Weibull $\boldsymbol{\alpha}(\boldsymbol{k V} / \mathbf{m m})$ & Weibull $\boldsymbol{\beta}$ \\
\hline $0 \mathrm{GHE}$ & $117.6 \pm 1.7$ & 21.7 \\
\hline $1 \mathrm{GHE}$ & $124.1 \pm 2.2$ & 20.1 \\
\hline $4 \mathrm{GHE}$ & $129.6 \pm 1.8$ & 24.6 \\
\hline $10 \mathrm{GHE}$ & $119.5 \pm 1.5$ & 26.0 \\
\hline $30 \mathrm{GHE}$ & $95.2 \pm 3$ & 11.9 \\
\hline
\end{tabular}

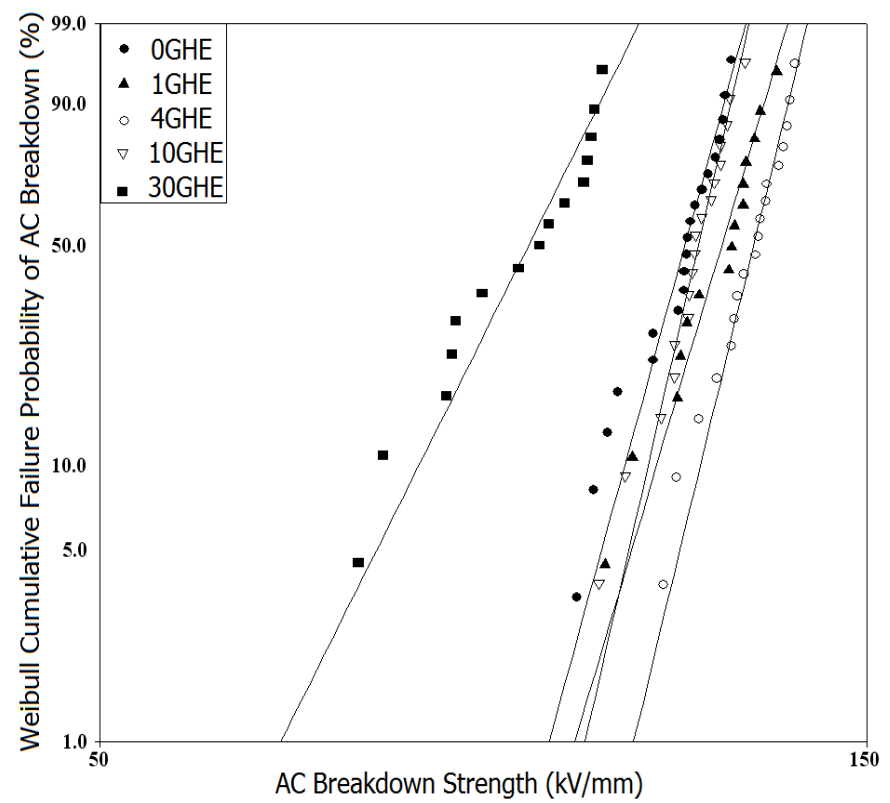

Fig. 3. Weibull plots of breakdown data obtained for neat and modified samples

\section{DISCUSSION}

Measurements of the glass transition temperature indicated that as the mass of reactive diluent increase, $T_{g}$ shifts to lower values. This could be explained by the fact that the added diluent contains a long chain alkyl group $\left(\mathrm{C}_{19} \mathrm{H}_{38} \mathrm{O}_{2}\right)$, which would be expected to introduce free volume in the system when reacted into the resin network. The created volume assists in large-scale molecular motion, which consequently decrease the $T_{g}$ of the systems. These results are consistent with the results reported by Liu et al. in [7] for epoxy resin systems modified using a reactive diluent containing an alkyl chain.

According to Andritsch [6], the observed dielectric response of epoxy resin systems is linked to $T_{g}$; the $\alpha$-relaxation, which is usually evident below $100 \mathrm{~Hz}$ in the imaginary part of complex permittivity, is associated with $T_{g}$. This association of the dielectric $\alpha$-relaxation and $T_{g}$ explains the rising peak seen in the imaginary permittivity data shown in Fig. 2 for 30GHE, which is in line with the temperature dependence of the dielectric response of epoxy resins [8].

In addition, the high frequency peak in the imaginary permittivity (above $10^{4} \mathrm{~Hz}$ ) in all systems other than $30 \mathrm{GHE}$ is attributed to the $\beta$-relaxation. It was stated in [9] and [10], that $\beta$-relaxation is associated with the movement and frequency of the hydroxyether groups in epoxy resin system. These hydroxyether groups are generated by the reaction of the amine hydrogen of the hardener and the epoxide groups in the system. In this work, epoxide groups are being introduced to the system from the epoxy resin in addition to the epoxybased reactive diluent. As the results indicated that the introduction of reactive diluent decreased the $\beta$-relaxation, this might indicate that the increased addition of the reactive diluent could have resulted in systems with lower amounts of hardener, which would directly affect the formation of 
hydroxyether groups and, consequently, contributed to the slight reduction of the $\beta$-relaxation peak. In addition to the effect of the reactive diluent on the number of hydroxyether groups, the movement of these groups might have also been environmentally constrained by the integration of the reactive diluent within the epoxy resin network which would also contributed to the decrease in $\beta$-relaxation. It should be noted that the relaxation behavior of $30 \mathrm{GHE}$ does not follow similar trend to other samples, where it is suggest that the dielectric relaxation of the hydroxyether groups formed by reaction of Jeffamine and the $30 \mathrm{GHE}$ is different, and does not contribute to $\beta$-relaxation.

The breakdown strength data reported here indicates that the inclusion of high percentages, $30 \%$ of epoxide groups from the reactive diluent, significantly reduces the breakdown of the system. However, the addition of up to $4 \%$ of epoxide groups from the reactive diluent increase the breakdown strength of the modified systems. This is unexpected as the added GHE diluent has no electroactive character. The reactive diluent appears to act through the introduction of aliphatic branches into the network. These branches affect the density of the epoxy network and thereby modifies the mechanical properties of the system; this could, in turn, have have consequences for breakdown strength of the system [11]. This behavior could have also influenced the conductivity, as the initial DC conductivity of neat epoxy resin was in the range of $10^{-17}$ which was increased as a function of reactive diluent where the measured DC conductivity of 30GHE increased by 3 orders of magnitude. DC conductivity measurements for filled epoxy systems conducted by Andritsch et al. [12] stated that the addition of nano-fillers could have generated areas with easy charge transport which resulted in reduced conductivity. This could be similar to the behavior reported here for epoxy resin modified by reactive diluent. Other behaviors of the reactive diluent modified system is comparable to that of nanocomposite where the decreased $T_{g}$ is similar to results reported for nano-fillers by Becker [13]. Furthermore, the variation in the breakdown strength with increasing diluent mass is similar to the behavior of boron nitride nano-fillers reported by Tsekmes [5]. It seems that epoxy-based reactive diluents might have similar effect on the behavior of epoxy resin systems as nano-fillers. If this anticipation were correct, then reactive diluent with suitable R-terminal group would replace the need to use nano-fillers.

\section{CONCLUSIONS}

The effect of modifying epoxy resin network structures by introducing an epoxy-based reactive diluent has been studied. The addition of GHE altered the free volume in the epoxy resin system, which resulted in a progressive reduction in $T_{g}$. The real part of the relative permittivity also fell as the added fraction of the reactive diluent increased. The dielectric $\alpha$ relaxation increased, affected by the variation in $T_{g}$. In addition, the strength of the $\beta$-relaxation decreased which were attributed to the frequency of hydroxyether groups and their movement which were constrained by the integration of the reactive diluent in the epoxy matrix. Furthermore, the breakdown strength increase up to certain mass of reactive diluent which was ascribed to the formation of aliphatic branches in the network which altered the breakdown strength. Finally, the addition of reactive diluent changed the DC conductivity. The behavior of $T_{g}$, permittivity, breakdown strength and DC conductivity reported here for GHE modified epoxy resin systems are comparable to the behavior reported in literature for nanocomposites. Therefore, it is suggested that engineering an insulation system modified with suitable reactive diluent would tailor the different properties of epoxy resin systems according to the needs of different applications.

\section{ACKNOWLEDGMENT}

The authors would like to thank the Schlumberger Foundation Faculty for the Future for the financial support.

\section{REFERENCES}

[1] EIA US., "Annual Energy Outlook 2016 Early Release: Annotated Summary of Two Cases," US Energy Inf. Adm. May, 2016.

[2] T. Line, "Performance of HV Transmission Line Insulators in Desert Conditions Part I: Review of Research and Methods Adopted Internationally," IEEE Trans. Electr. Insul., no. 2, 1983.

[3] G. Iyer, R. Gorur, R. Richert, a. Krivda, and L. Schmidt, "Dielectric properties of epoxy based nanocomposites for high voltage insulation," IEEE Trans. Dielectr. Electr. Insul., vol. 18, no. 3, pp. 659-666, 2011.

[4] S. Nishanth, M. Kaviarasu, and N. Mallireddy, "Thermal Properties of Modified Epoxy Nano Composite," Int. J. Eng. Res. Technol. (IJERT)., vol. 3, no. 3, pp. 304-305, 2014.

[5] I. A. Tsekmes, R. Kochetov, P. H. F. Morshuis, and J. J. Smit, "AC Breakdown Strength of Epoxy-Boron Nitride Nanocomposites: Trend \& Reproducibility," Electr. Insul. Conf., no. June, pp. 446449, 2015.

[6] T. Andritsch, "Epoxy Based Nanodielectrics for High Voltage DC Applications: Synthesis, Dielectric Properties and Space Charge Dynamics," Doctoral dissertation, Delft University of Technology, 2010.

[7] Y. Liu, A. S. Vaughan, I. L. Hosier, C. Yeung, and T. Andritsch, "On epoxy network structure and dielectric performance," in Electrical Insulation and Dielectric Phenomena (CEIDP), IEEE Conference, 2015, pp. 114-117.

[8] R. Casalini, D. Fioretto, A. Livi, M. Lucchesi, and P. A. Rolla, "Influence of the glass transition on the secondary relaxation of an epoxy resin," Phys. Rev. B, vol. 56, no. 6, pp. 3016-3021, 1997.

[9] T. V. Kosmidou, A. S. Vatalis, C. G. Delides, E. Logakis, P. Pissis, and G. C. Papanicolaou, "Structural, mechanical and electrical characterization of epoxy-amine/carbon black nanonocomposites," Express Polym. Lett., vol. 2, no. 5, pp. 364-372, 2008.

[10] P. Pissis and D. Fragiadakis, "Dielectric studies of segmental dynamics in epoxy nanocomposites.," J. Macromol. Sci. Part B Phys., pp. 119-136, 2007.

[11] J. P. Jones, J. P. Llewellyn, and T. J. Lewis, "The Contribution of Field-Induced Morphological Change to the Electrical Aging and Breakdown of Polyethylene," Dielectr. Electr. Insul. IEEE Trans., vol. 12, no. 5, pp. 951-966, 2005.

[12] T. Andritsch, R. Kochetov, P. H. F. Morshuis, and J. J. Smit, "DC conduction in epoxy based nano- and mesocomposites," Electr. Insul. Dielectr. Phenom. (CEIDP), IEEE Conf., 2010.

[13] O. Becker, R. Varleyb, and G. Simon, "Morphology, thermal relaxations and mechanical properties of layered silicate nanocomposites based upon high-functionality epoxy resins," Polymer (Guildf)., vol. 43, no. 16, pp. 4365-4373, 2002. 